Available online at: https://proceeding.researchsynergypress.com/index.php/rsfconferenceseries1

RSF Conference Series: Business, Management and Social Sciences

e-ISSN 2807-5803/ p-ISSN 2807-6699

Volume 1 Number 1 (2021): 20-29

\title{
Intervening Effect of Hybrid Method in Enhancing Teachers' Engagement and Satisfaction
}

\author{
Jennifer Operio
}

School of Business and Accountancy, Holy Angel University, Philippines

\begin{abstract}
This research examined the intervening effect of technology expressed as the hybrid method or approach in enhancing teachers' engagement and satisfaction in imparting knowledge to the Senior High School level of Holy Angel University (HAU). It particularly sought answers to the following: (1) Is the hybrid learning approach being utilized in teaching subjects to HAU's Accountancy, Business and Management (ABM) strand students? (2) What are the barriers to using hybrid learning techniques in teaching these HAU's ABM strand students? (3) How may the level of effectiveness be described in using a hybrid learning technique? (4) What are the advantages of utilizing hybrid approach as a teaching method? (5) What is the most/least effective aspect of hybrid learning as a teaching method?
\end{abstract}

Descriptive-quantitative research was utilized. Fifty senior high school teachers teaching ABM strand students are targeted. However, only 35 filled-out survey forms were turned in. The utilization or possible integration of technology in teaching subjects to students at the Senior High School level was identified. Ethical considerations were employed in conducting this research: respect for anonymity and confidentiality of the information collected; respect for privacy - respondents were given ample time in answering the survey questionnaire; they were protected in such a way that they did not feel intimated, the proponent let another person conduct the survey and was not directly involved with the distribution and collection of the survey instrument.

Validation of the instrument was also done through a group of people with similar characteristics to the respondents of the study. An expert in research and statistics with so many years of experience doing researches were also consulted. Results show that though teachers utilized the hybrid approach, a small percentage of them still fully utilized the traditional approach in providing information to their learners. Technology and advancements have their own pros and cons. Research could be made to have equal.

Footing for all types of students on the utilization and application of technology to the current curriculum of the ABM strands without letting the more emphatic way of addressing their needs. As a recommendation, the researcher proposes further research that could be triangulated, which will involve students and school administrators to further validate the mediating effect of hybrid learning on students engagement.

Keywords: Traditional teaching-learning; SAMR model; A hybrid approach

This is an open access article under the CC-BY-NC license

\section{INTRODUCTION}

In the Philippines, Revised/ Enhanced Educational System, Senior High School (SHS) pertains to the last two years of the $\mathrm{K}+12$ program. This covers Grades 11 and 12. Under this new curriculum set-up, Learners are required to undergo a core curriculum and subjects under a track of their choice (Dep Ed, 2015). At the SHS level, a learner can choose among three tracks. One of these is the Academic track which includes the Accountancy, Business Management (ABM) strand. Even though a competitive spirit is

Corresponding author

Jennifer Operio, joperio@hau.edu.ph

DOI: https://doi.org/10.31098/bmss.v1i1.250

Research Synergy Foundation 
prevalent in the citizenry, the country's current education system hinders us from becoming even more competitive. Commencing in the school year 2012-2013, an enhancement was adapted from the ten years of basic education to a 12-year program through an initiative called the $\mathrm{K}$ to 12 Education Plan sponsored by the Department of Education. The program offers a decongested 12-year program that gives students sufficient time to master skills and absorb basic competencies. It also accelerates mutual recognition of Filipino graduates and professionals in other countries (K to 12 Philippines, 2015)

The ABM strand focuses on the basic concepts of financial management, business management, corporate operations, and all things that can be accounted for. ABM strand for Grades 11 and 12 started two years back in the university as a result of the $\mathrm{K}$ to 12 educational objectives of the Philippine government. It is designed as an introductory course in accounting and business and management where students are trained to think logically and scientifically and are acquainted with the concepts and processes of accounting, business and management theories and principles in preparation for their college degrees that focus on business and industry where their contribution as future accountants, entrepreneurs, and business leaders are vital to the progress and development of the economy and critical to the promotion of a sustainable green business. The School of Business and Accountancy is the only school in the entire university that caters to these ABM strand graduates from the Senior High School.

The F2F set-up is more likely to be for organized activities that practically apply the syllabus to solve problems or work through tasks (Poon et al., 2010). A single term of hybrid learning can utilize F2F time at the onset and slowly raise the bar of tasks that learners actively do synchronously or at self-paced study time. However, some debate that a discussion forum inside the study hall is better if the students and teachers have seen each other first (Donnelly, 2010). In other instances, the shift to mixed approach learning has motivated teachers to revitalize roles. The 'facilitator' puts stress on empowering students with talents, knowledge and skills basically needed to utilize the majority of the resources and self-paced study time online, leading learners to the best exciting and valuable experience (Puentedura, 2014).

Those so-called "facilitators" look at four important factors:

1. Developing synchronous and asynchronous lesson types.

2. Guiding learners in communication with and among them, which includes the pedagogical aspect in content online without using contextual clues.

3. Assisting the studying modalities of each learner and editing resources whenever possible to improve the studying experience.

4. Evaluating and assessing, like the anticipation for teachers within the customary scaffolding.

Biggs and co-authors state that giving emphasis on learning through guided and standard activities, the hybrid approach of learning proved to be more flexible to what other institutions and organizations are considering hybrid training. Through this approach, trainers can transfer their focal point from the knowledge impartation to its actual experience, and organizations incur fewer expenses in transporting their trainers anywhere just to manage the entire training activities and events (Biggs et al., 2011). The mixed-method can become an effective option if educational institutions are looking for other ways to provide their learners with a more customary experience in their studies without worrying about stretching their finances. It mixes actual F2F instruction accompanied by synchronous studying. It has yielded significant outcomes since initially researched as a strategy in education. The US Department of Education in 2010 statistically discovered that mixed-method classes had produced significant outcomes than their F2F, non-combined counterparts. The main reason is that this increasingly growing technique not only attracts flexible and individualized learning mode. It also allows educators to extend the time they utilize as guides of learning. Most educational institutions switched to a hybrid form of learning for so 
many reasons. And with several additional summative assessment questions. It is easier to redefine and transform classroom tasks with classroom technologies.

The research framework portrays the intervening, independent and dependent variables. The subject respondents are the independent variables, and the hybrid learning techniques are the intervening variables. While the dependent variables are the results of the study and accompanying recommendations for future researches. There is also an aim to summarize recommendations or suggestions in the most and least effective aspect of blended learning.

Figure 1 illustrates the operational framework utilizing Hybrid Learning (HL) as the mediating effect in teaching students at the SHS level, including the teachers' satisfaction. As shown in the framework, the hybrid approach as utilized was examined in its mediating effect on teaching students in Senior High School, particularly the ABM strand students of the Holy Angel University - Basic Education Department.

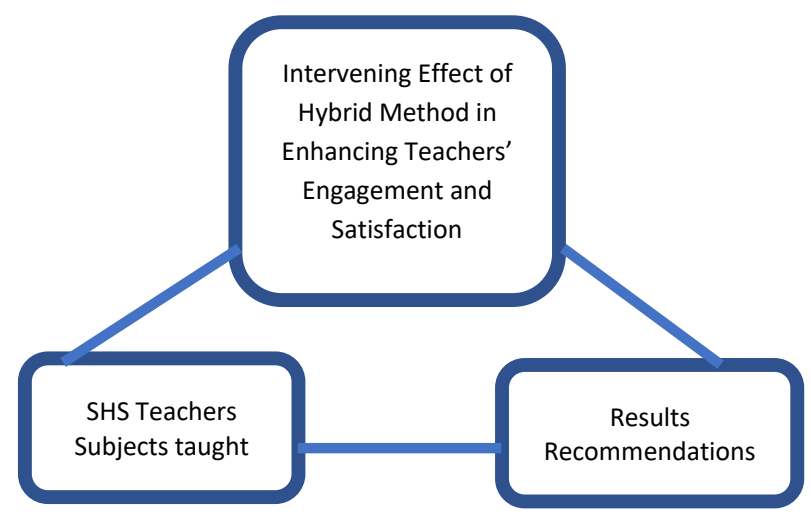

Figure 1. Operational Framework

This research examined the mediating effect of technology expressed as the hybrid learning approach to students' learning, particularly in the Senior High School level of Holy Angel University. It serves as a springboard into a possible redefinition of the approach to the teaching of the educators through integrating other forms of teaching methodologies to augment classroom learning. Particularly, it sought to answer the following:

1. Is the hybrid learning approach being utilized in teaching subjects to HAU's ABM strand students?

2. What are the barriers to using hybrid learning techniques in teaching these HAU's ABM strand students?

3. How may the level of effectiveness be described in using a hybrid learning technique?

4. What are the advantages of utilizing hybrid approach as a teaching method?

5. What is the most/least effective aspect of hybrid learning as a teaching method?

\section{MATERIALS AND METHODS}

Research Design

The researcher utilized descriptive-quantitative research. Fifty senior high school teachers teaching ABM strand students were targeted. However, only 35 filled-out survey forms were returned as of October 17 2018, or more than two weeks after permission was sought from the school principal. A possibility of integrating technology through the learning management system in teaching subjects to students in the Senior High School level of the Holy Angel University was identified. 
Participants or Respondents

The respondents of the study were teachers who are teaching ABM strand in Senior High School of the Holy Angel University. Initially, 50 respondents are targeted; however, there were only 35 respondents who submitted the filled-out survey forms. The youngest age of the participants is 20 , and the oldest is 47 . With regard to the gender classification, 17 are males, and 18 are females.

\section{Research Instrument}

The researcher utilized a survey questionnaire, which is self-made, in getting accurate information. The questionnaire was designed in such a way that the participants can easily understand what was being asked. It is composed of the subjects taught by the teachers. In order to validate the instrument used in the research, a pilot test to 20 teachers teaching in secondary school with similar characteristics as the respondents of the study was done. The result of the pilot testing showed that some words or phrases in the instrument are a little bit confusing. To address this, rewording was done to some questions in the questionnaire. Reliability was attained through the inter-rater reliability in which the instrumentation was tested on a different group of people. Also, an expert in research and statistics was also consulted.

Section 1 focused on the respondents' experience of using blended learning approach. Section 2 is about their satisfaction in using blended learning, while Section 3 was on the comments about blended learning. Under Section 1, the first question was answered by either yes or no. Additional information is needed when the respondent replied "yes", so that the researcher can get a more understanding on how the hybrid approach is being utilized by the teacher. However, if the respondent answered yes, additional information is requested. Question number 2 is just a choice from the respondents. While the third question is using the five-point Likert Scale; $5=$ Most effective, $4=$ More effective, $3=$ Effective, $2=$ Less effective and $1=$ Least effective. For Section 2 which is about the overall satisfaction in using blended learning; a four-point Likert Scale will be used; $4=$ Strongly agree, 3=Agree, 2=Disagree and 1=Strongly disagree. The last section -Section 3 is about respondents' comments on the use of blended learning. This includes choosing the three topmost advantages of using hybrid learning, the most effective aspect and the least effective aspect of blended learning technique as an approach to teaching.

\section{Data Gathering Procedures}

The researcher asked the permission of the Basic Education Principal verbally and in writing. The SHS Coordinator facilitated the distribution of the survey questionnaires to respondents. Prior to the actual survey, the researcher opted to have a face-to-face meeting with the principal to verbally ask for approval. Once the request was granted, the researcher submitted a letter to the office of the principal. The letter was endorsed to the senior high school coordinator for distribution of the survey forms. As ethical consideration, the proponent did not directly participate in the distribution and collection of survey forms.

\section{Data Analysis}

The researcher classified, tallied and organized the information into tables and according to paradigm using qualitative and quantitative terms.

The statistical tools that were utilized are Frequency, Percentage and Weighted Means to describe the questions. Frequency and percent were used for data that are nominal. Weighted Means were computed for questionnaire items that are on a 5-point and 4-point rating scales. The following tables were used to evaluate the ordinal data: 
Table 1.5-point Likert Scale

\begin{tabular}{|c|c|c|}
\hline Likert Scale (1) & Likert Description (2) & Value Allocation (3) \\
\hline 1 & Least effective & $1.00-1.49$ \\
\hline 2 & Less effective & $1.50-2.49$ \\
\hline 3 & Effective & $2.50-3.49$ \\
\hline 4 & More Effective & $3.50-4.49$ \\
\hline 5 & Most Effective & $4.50-5.00$ \\
\hline
\end{tabular}

Table 2. 4-point Likert Scale

\begin{tabular}{|c|c|c|}
\hline Likert Scale (1) & Likert Description (2) & Value Allocation (3) \\
\hline 1 & Strongly Disagree & $1.00-1.49$ \\
\hline 2 & Disagree & $1.50-2.49$ \\
\hline 3 & Agree & $2.50-3.49$ \\
\hline 4 & Strongly Agree & $3.50-4.00$ \\
\hline
\end{tabular}

Ethical Considerations

Ethical considerations were employed in conducting this research: respect for anonymity and confidentiality of the information collected; respect for privacy - respondents were given ample time in answering the survey questionnaire; they were protected in such a way that they did not feel intimated, the proponent let another person conduct the survey and was not directly involved with the distribution and collection of the survey instrument.

\section{FINDINGS AND DISCUSSION}

The study was an attempt to examine the effect of hybrid learning (HL) on students' engagement and learning satisfaction. As stated in the previous pages, the research targeted the senior high teachers of Holy Angel University, particularly those who are teaching the ABM strand students. There were 35 teachers who participated in the study. A survey was utilized to determine the integration of hybrid teaching and learning and its effectiveness. The results obtained were put through statistical analysis and are presented in this section.

Table 3 shows the age and gender distribution of the respondents composed of 35 Senior High School teachers in Holy Angel University who are teaching ABM strand students. The majority of the participants are from the age range of 25 years and below or about $40.00 \%$ of the total respondents, 20 as being the youngest. It is followed by the age group from 26 to 30 years of age which is about $20.00 \%$. Basically, males and females were well represented with 17 and 18 respondents, respectively. The age of the oldest participant is 47 and a female.

Table 3. Age and Gender

\begin{tabular}{|c|c|c|c|c|}
\hline \multirow{2}{*}{ Age } & \multicolumn{2}{|c|}{ Gender } & \multirow{2}{*}{ Frequency } & Percentage \\
\cline { 2 - 3 } & Male & Female & & \\
\hline 25 years and below & 9 & 5 & 14 & $40.00 \%$ \\
\hline 26-30 years & 5 & 2 & 7 & $20.00 \%$ \\
\hline 31-35 years & 2 & 4 & 6 & $17.14 \%$ \\
\hline 36-40 years & 0 & 2 & 2 & $5.72 \%$ \\
\hline 41-45 years & 1 & 2 & 3 & $8.57 \%$ \\
\hline
\end{tabular}




\begin{tabular}{|c|c|c|c|c|}
\hline 46 years and above & 0 & 3 & 3 & $8.57 \%$ \\
\hline Total & $\mathbf{1 7}$ & $\mathbf{1 8}$ & $\mathbf{3 5}$ & $\mathbf{1 0 0 \%}$ \\
\hline
\end{tabular}

Table 4 presents the subjects taught by the respondents alphabetically. Two participants are teaching Accounting 2. There are an equal number of respondents for the subjects: Culture, Society \& Politics; Philosophy of the Human Person; organization and management; marketing; and practical research. It shows the equal number of respondents for Applied Economics, English for Academic Purposes and Entrepreneurship.

Table 4. Subjects Taught

\begin{tabular}{|c|c|c|}
\hline Subjects & Frequency & Percentage \\
\hline Accounting 2 & 2 & $5.70 \%$ \\
\hline Applied Economics & 5 & $14.29 \%$ \\
\hline Culture, Society \& Politics & 4 & $11.43 \%$ \\
\hline English for Academics and Professionals & 5 & $14.29 \%$ \\
\hline Entrepreneurship & 5 & $14.29 \%$ \\
\hline Introduction to Philosophy of the Human Person & 4 & $11.43 \%$ \\
\hline Marketing & 4 & $11.43 \%$ \\
\hline Organization and Management & 3 & $8.57 \%$ \\
\hline Practical Research 1 & 3 & $8.57 \%$ \\
\hline Total & 35 & $100 \%$ \\
\hline
\end{tabular}

Table 5 describes the utilization of hybrid learning for teaching. It turned out that the majority of them are not utilizing the hybrid approach to teaching and learning their subjects. Only about 17 or $49.57 \%$ of the participants are using the blended approach. Most of them believed that it is still important to use the traditional method in teaching their subjects.

Table 5. Utilization of Hybrid Learning in teaching

\begin{tabular}{|c|c|c|}
\hline Answers & Frequency & Percentage \\
\hline Yes & 17 & $48.57 \%$ \\
\hline No & 18 & $51.43 \%$ \\
\hline Total & $\mathbf{3 5}$ & $\mathbf{1 0 0 \%}$ \\
\hline
\end{tabular}

The top barriers in utilizing HL, as shown in Table 6, are an unstable internet connection, with 20 of the participants or $34.29 \%$ choosing it as the number 1 . It is followed by a weak signal, then by the availability of internet at school, and availability of internet at home. Lastly, one respondent mentioned that it is not applicable to the subject he is teaching.

Table 6. Barriers in Utilizing Hybrid Learning

\begin{tabular}{|c|c|c|}
\hline Barriers & Frequency & Percentage \\
\hline Unstable Internet Connection & 12 & $34.29 \%$ \\
\hline Weak Signal & 9 & $25.71 \%$ \\
\hline Availability of Internet at school & 6 & $17.14 \%$ \\
\hline Availability of Internet at home & 5 & $14.29 \%$ \\
\hline Others: Not applicable to the Subject & 3 & $8.57 \%$ \\
\hline Total & $\mathbf{3 5}$ & $\mathbf{1 0 0 \%}$ \\
\hline
\end{tabular}


The level of effectiveness of the blended approach using the Likert scale as shown below depicts that it is more effective with the final figure of 3.66.

Table 7. Level of Effectiveness of Hybrid Learning

\begin{tabular}{|c|c|c|c|c|}
\hline $\begin{array}{c}\text { Likert Scale } \\
\text { (1) }\end{array}$ & $\begin{array}{c}\text { Likert Description } \\
\text { (2) }\end{array}$ & $\begin{array}{c}\text { Value } \\
\text { Allocation (3) }\end{array}$ & $\begin{array}{c}\text { Frequency } \\
\mathbf{( 4 )}\end{array}$ & Sum[(1)*(4)]/n \\
\hline 1 & Least effective & $1.00-1.49$ & 5 & 5 \\
\hline 2 & Less effective & $1.50-2.49$ & 5 & 10 \\
\hline 3 & Effective & $2.50-3.49$ & 6 & 18 \\
\hline 4 & More Effective & $3.50-4.49$ & 10 & 40 \\
\hline 5 & Most Effective & $4.50-5.00$ & 9 & 45 \\
\hline & More Effective & & $\mathbf{3 5}$ & $\mathbf{1 2 8 / 3 5 = 3 . 6 6}$ \\
\hline
\end{tabular}

The participants, in general, as depicted by Table 8 , would still agree to have another term of utilizing a hybrid learning approach in teaching within the next school year. The final figure shows 2.97 and is interpreted as Agree.

Table 8. Have another hybrid learning approach in teaching

\begin{tabular}{|c|c|c|c|c|}
\hline $\begin{array}{c}\text { Likert Scale } \\
(\mathbf{1})\end{array}$ & $\begin{array}{c}\text { Likert Description } \\
\text { (2) }\end{array}$ & $\begin{array}{c}\text { Value } \\
\text { Allocation (3) }\end{array}$ & $\begin{array}{c}\text { Frequency } \\
\mathbf{( 4 )}\end{array}$ & Sum[(1)*(4)]/n \\
\hline 1 & Strongly Disagree & $1.00-1.49$ & 5 & 5 \\
\hline 2 & Disagree & $1.50-2.49$ & 5 & 10 \\
\hline 3 & Agree & $2.50-3.49$ & 13 & 39 \\
\hline 4 & Strongly Agree & $3.50-4.00$ & 12 & 48 \\
\hline & Agree & & $\mathbf{3 5}$ & $\mathbf{1 0 2} / \mathbf{3 5}=\mathbf{2 . 9 1}$ \\
\hline
\end{tabular}

The overall satisfaction rating of the 35 participants is 2.91, which mean they all agree and are satisfied with the hybrid learning approach in teaching. Table 9 also shows that there are 2 participants who chose strongly disagree as to the answer.

Table 9. Overall satisfied with hybrid learning

\begin{tabular}{|c|c|c|c|c|}
\hline $\begin{array}{c}\text { Likert Scale } \\
\text { (1) }\end{array}$ & $\begin{array}{c}\text { Likert Description } \\
\text { (2) }\end{array}$ & $\begin{array}{c}\text { Value } \\
\text { Allocation (3) }\end{array}$ & $\begin{array}{c}\text { Frequency } \\
\text { (4) }\end{array}$ & $\operatorname{Sum}\left[(1)^{*}(4)\right] / n$ \\
\hline 1 & Strongly Disagree & $1.00-1.49$ & 2 & 2 \\
\hline 2 & Disagree & $1.50-2.49$ & 11 & 22 \\
\hline 3 & Agree & $2.50-3.49$ & 8 & 24 \\
\hline 4 & Strongly Agree & $3.50-4.00$ & 14 & 56 \\
\hline & Agree & & 35 & $104 / 35=2.97$ \\
\hline
\end{tabular}

As per the comments of the participants about hybrid learning, table 10 presents the top four answers on the advantages of utilizing the HL. Flexibility in completing assignments is number one, with 12 respondents or $34.28 \%$ choosing it. It is followed by convenience, 9 participants or $28.37 \%$. There are some who answered, "it is a requirement for the course" and lastly is the "only available option". 
Table 10. Advantages of using hybrid learning

\begin{tabular}{|c|c|c|}
\hline Advantages & Frequency & Percentage \\
\hline Flexibility to complete assignments & 12 & $34.28 \%$ \\
\hline Convenience & 10 & $28.57 \%$ \\
\hline It is a requirement for course & 8 & $22.86 \%$ \\
\hline The only available option & 5 & $14.29 \%$ \\
\hline Total & $\mathbf{3 5}$ & $\mathbf{1 0 0 \%}$ \\
\hline
\end{tabular}

Table 11 presents the top five choices of the respondents in terms of the most effective aspect of HL. The number one answer is; convenience with $34.29 \%$, followed by technological advancement and effective teaching and learning process. Four of the respondents answered that it made use of the time efficiently and, lastly, that it provides a broader source of information.

Table 11. The most effective aspect of hybrid learning

\begin{tabular}{|c|c|c|}
\hline Most Effective & Frequency & Percentage \\
\hline Convenience & 12 & $34.29 \%$ \\
\hline Technological Advancement & 9 & $25.71 \%$ \\
\hline Effective teaching and learning process & 7 & $20.00 \%$ \\
\hline Time Efficiency & 5 & $14,29 \%$ \\
\hline Broader Source of Information & 2 & $5.71 \%$ \\
\hline Total & $\mathbf{3 5}$ & $\mathbf{1 0 0} \%$ \\
\hline
\end{tabular}

Finally, in Table 12, the least effective aspect of HL is that there is a form of abuse because it is now easier through technology to educate oneself. Based on the results, some teachers mentioned that it had replaced the old way of interacting inside the four-walled classroom. Students nowadays are more dependent on technological access leading to less dependence on books in the library. Secondly, unavailability of the internet in most parts of the province or area. Lastly is the unequal chance to have access to technology.

Table 12. The least effective aspect of hybrid learning

\begin{tabular}{|c|c|c|}
\hline Least Effective & Frequency & Percentage \\
\hline Abuse since education is easier & 15 & $42.86 \%$ \\
\hline Unavailability of Internet & 12 & $34.28 \%$ \\
\hline Unequal Access to technology & 8 & $22.86 \%$ \\
\hline Total & $\mathbf{3 5}$ & $\mathbf{1 0 0 \%}$ \\
\hline
\end{tabular}

\section{CONCLUSION}

This study is in agreement with that of Horn and Staker (2011), indicating that computers are widely used by learners and teachers. The integration and utilization of technology are affecting the present way of delivering information and teaching the new breed of students - the millennials. The results also provide some fascinating insights into the continuous use of traditional teaching-learning in our present education system. The study by Puentedura (2014) also shows that the stages of using technology may start from the base, which is substitution. This proves that some may be shifting to technology, but traditional teaching is still very much applied, and technology is just a substitute. As per answers of 
respondent-teachers, age and gender have no direct relationship whether a teacher will use traditional teaching methods or take advantage of technology in their teaching style. As a matter of fact, the utilization of the hybrid approach is based on the topic and the subject. It is also interesting to note that dependent upon the subject being taught, that technology may be applicable or not. The study made by Maly (2014) contradicts this result which states that students who were given enough time to learn from the teaching materials provided to them became successful and earned a degree at the age of twenty-five. The results also show that most teachers are still amenable to a face-to-face discussion of the topics rather than take advantage of social media or online communication. The findings contradict that of the study made by Maly (2014), where it was discussed that an educator prefers giving more flexible time to students in their studies. Likewise, it's interesting to note that based on the results, some agree that a mixed approach can get the interest of learners as well as help them to be more engaged. This is also in agreement with the study made by Nelson (2018), indicating that students became more active and challenged themselves to work harder using the available materials given to them.

\section{FURTHER RESEARCH}

The following recommendations for research are based on study findings; Unavailability of the Internet in school is a significant barrier to integrating technology and hybrid learning and teaching approach in the senior high school level of the Holy Angel University. More research is needed to identify effective ways on how to make the internet more available in school and the classroom. Research should address the structural and attitudinal barriers and how these might be overcome.

Weak signals and unstable internet connection proved to be other significant barriers in applying the blended learning approach. Research could explore the possible ways to allow the international telecommunications company to break the long period of oligarchy in the telecommunications industry. This would also need to address monopolistic control of the industry, giving way to equal chances to every learner in every area of the country and whatever family earning level they are in.

The educators themselves are confused about applying technology and a blended approach to their teaching methods. Further research can be explored on the reasons for such confusion among teachers. This should look into deeper issues such as lack of training in terms of technology and adapting an elearning educational system for the school. The research should also assess training needs and readiness in utilizing technology in teaching.

Further research that could be triangulated will involve students and school administrators to further validate the mediating effect of hybrid learning on students' engagement.

\section{REFERENCES}

Biggs, J., \& Tang, C. (2011). Teaching for quality learning at university (4th Ed.). Maidenhead, UK: Open University Press

Department of Education (2015). The K to 12 Program. Philippines. Retrieved from http://www.deped.gov.ph/k-to-12/about/k-to-12-basic-education-curriculum/

Donnelly, R. (2010). Harmonizing technology with interaction in blended problem-based learning. Computers \& Education, 54(2), 350-359.doi10.1016/j.compedu.2009.08.

Horn, Michael /b. \& Staker, Heather (2011). The Rise of K-12 blended learning. Innosight Institute.

Maly, Ken (2014). 6 Models of blended learning. Retrieved from https://www.wlu.ca.spotlight.ken.maly.html 
Nelson, Regina (2018). Six Models of Blended Learning. Retrieved from https://www.uwplatt.edu/icet-news/six-models-blended-learning

NMC Red Archive (2012). Ruben Puentedura, Board Member. Retrieved from http://redarchive.nmc.org/ruben-puentedura-board-member

Operio, Jennifer H. (May, 2019). Impact assessment of technology to a private college in Bulacan, Philippines: The mediating effect of hybrid approach. Paper presented at 2019 IRES International Conference, Manila, Philippines. IJMAS-IRAJ-DOI15507.

Poon, J., Royston, P., \& Fuchs, W. (2010, September). An examination of the critical factors for Developing a successful blended learning teaching method for RICS and CIOB Accredited courses paper presented at the RICS Foundation Construction and Building Research Conference (COBRA 2010), Paris, France.

Puentedura, R. (2003, July 15). An Introduction [Web log post]. Retrieved from http://www.hippasus.com/rrpweblog/archives/000001.html

Puentedura, R. (2014), September 24). SAMR and Bloom's Taxonomy: Assembling the Puzzle [Web log post]. Retrieved from https://www.graphite.org/blog/samr-and-blooms-taxonomy-assembling-thepuzzle.

Puentedura, R. (2014, November 12). SAMR: First Steps [Presentation slides]. Retrieved from http:www.hippasus.com/rrpweblog/archives/2014/11/13/SAMR_FirstSteps.pdf

Smyth, S., Houghton, C., Cooney, A., \& Casey, D. (2012). Students' experiences of blended learning across a range of postgraduate programmes. Nurse Education Today, 32(4), 464-468, doi:10.1016/j.nedt.2011.05.014 